\title{
TRANSIENT PAROTITIS IN THE COURSE OF CLOZAPINE TREATMENT: A CASE REPORT AND REVIEW OF THE LITERATURE
}

\author{
Koraliya Todorova-Nenova \\ Department of Psychiatry and Medical Psychology, Faculty of Medicine, \\ Medical University of Varna
}

\begin{abstract}
INTRODUCTION: Clozapine is an atypical antipsychotic, treatment of choice for patients unresponsive to, or intolerant of other antipsychotic drugs. While most of the adverse effects of clozapine are well discussed in the literature, clozapine-induced parotitis emerges as an uncommon complication, which clinicians should be aware of.

AIM: The aim of this report is, by illustrating a case of clozapine-induced parotitis and reviewing the literature on the topic, to bring awareness of the occurrence of this potential adverse effect of clozapine treatment.

CASE PRESENTATION: Due to poor response to several adequate trials with different antipsychotic medications a 57-year-old female with schizoaffective disorder was initiated on clozapine in 2008. The psychiatric condition of the patient notably improved in the following years. In 2016, after a decrease in her psychotropic therapy, the patient was hospitalized, and while restoring treatment with clozapine and divalproex she complained of increased salivation combined with painful bilateral parotid enlargement. The diagnosis of clozapine-induced parotitis was suggested. The medical condition had a favorable outcome within five days after administration of symptomatic medication.

CONCLUSION: Adherence to drug treatment in psychiatric patients can be significantly improved if patients are well informed about the potential adverse effects of the administered medications and if the clinicians recognize and try to resolve them. Monitoring both common and rare adverse effects of clozapine treatment will give patients a chance of better therapy management.
\end{abstract}

Keywords: clozapine, parotitis, adverse drug reactions

Address for correspondence:

Koraliya Todorova-Nenova

Faculty of Medicine

Medical University of Varna

55 Marin Drinov St

9002 Varna

e-mail: koralia.todorova@yahoo.com

Received: April 1, 2018

Accepted: June 29, 2018

\section{INTRODUCTION}

Clozapine is a unique molecule with respect to both beneficial and adverse effects. Introduced in the 1970s, it was withdrawn a few years later due to fatal cases of agranulocytosis. However, recently after that, it was "rediscovered" with the recognition of the most effective atypical antipsychotic and treatment of choice in refractory schizophrenia, which is estimated to affect up to $30 \%$ of all patients suffer- 
ing from schizophrenia $(1,2)$. While some of the adverse effects of clozapine as weight gain and metabolic abnormalities, possible hematological toxicity, risk of sedation and sialorrhea are well discussed in the literature (3), clozapine-associated parotitis emerges as an uncommon complication, which clinicians should be aware of (4).

Described is the clinical case of a 57-year-old woman who developed parotitis in the course of eight-year-long clozapine treatment. Patient's verbal consent for the case report was obtained.

\section{CASE PRESENTATION}

Mrs A.P. is a widow with two grown-up daughters. The history of her schizoaffective disorder dates back to 1975 when it presented with a depressive episode. A year later she was diagnosed with a manic episode accompanied with some disorder of thinking and mood-incongruent delusions. Her course over the next 30 years has been marked by annual recurrences, either manic or depressive in nature, most of them associated with mood-incongruent psychotic symptoms. Although Mrs P. has generally done well between episodes in the first years of her illness, she was unable to keep a permanent job and claimed for disability support pension. Her psychiatric condition deteriorated after 2005, marked by increased frequency and severity of her schizoaffective episodes. Following a hospital admission during which her psychiatric symptoms responded only slightly to two well-conducted antipsychotic trials with haloperidol and quetiapine, in August 2008 the patient was initiated on clozapine, which was never increased to more than $200 \mathrm{mg} /$ day. Clozapine was augmented with $1000 \mathrm{mg} /$ day divalproex. Over the next years Mrs P. experienced notable improvement and seemed compliant with treatment. She reported higher selfesteem and better social interactions. She reunited with her family, started living with one of her daughters and helped with the household chores. She also managed a part-time job. In the autumn of 2016, following a decrease in the dose of clozapine, Mrs P. was hospitalized for a relapse of her schizoaffective disorder with depressive and mood-incongruent paranoid symptoms. She was treated with $150 \mathrm{mg} /$ day clozapine and $1000 \mathrm{mg} /$ day divalproex was reinitiated together with $10 \mathrm{mg} /$ day escitalopram. Nineteen days later, Mrs P. exhibited substantial improvement of her psychiatric symptoms but complained of painful bilateral parotid swelling combined with increased salivation. The patient was apyretic, with physiological variables within normal range. Once a viral or bacterial etiology was ruled out, Mrs P. was seen by a maxillofacial specialist and parotitis was confirmed by ultrasound. Biperiden was added to the treatment and the patient was closely observed. The medical condition had a favorable outcome within five days.

\section{DISCUSSION}

Our case report illustrates bilateral parotitis after clozapine dose adjustment in the course of an eight-year-long clozapine treatment in a patient experiencing hypersalivation.

The swelling and inflammation of one or both salivary glands is considered as parotitis. While unilateral parotitis is attributed mainly to ductal obstruction, the inflammation and swelling of both parotid glands is more likely to reflect systemic causes (5). Drug-induced parotitis is a very uncommon adverse reaction, which may be caused by different drugs (4). It is among the least prominent side effects observed in patients on clozapine treatment (6).

The methods proposed, evaluating the causal role of a drug treatment in the occurrence of an adverse medical event, can be generally classified under three large categories: expert judgement, operational algorithms and probabilistic methods (7). The system of assessment introduced by the World Health Organization Collaborating Centre for International Drug Monitoring, the Uppsala Monitoring Centre (WHO-UMC), and the Naranjo Probability Scale, both outlining a relatively simple methodology, are among the most widely accepted methods of causality assessment of adverse drug reactions used in clinical practice. Moreover, the above scales proved to be structured, transparent and consistent $(8,9)$. The WHO-UMC system is a joint assessment tool evaluating both the clinico-pharmacological details of the case history and the quality of the medical records documenting the case. This method gives guidance to the general assessment criteria, helping to select one category over another $(9,10)$. When assessed under the WHO-UMC causality categories, our case was identified in the "probable/likely" category. The probability that a causal link exists between an untoward reaction and drug therapy is classified by the 
Naranjo criteria based on a list of weighted questions examining aspects like the time relation to the administration of the medication and the detection and progression of the adverse event, alternative causes for its occurrence, blood levels of the administered drugs, and previous patient experience with them. Recently the Naranjo adverse drug reaction probability scale has been utilized to evaluate causality for drug-induced parotitis (4). Scoring 6 on the parotitisspecific criteria modified Naranjo probability scale, the swelling of the salivary glands of the patient in our case report was probably caused by clozapine.

We searched Medline, Scopus and Science Direct for articles relevant to clozapine-induced parotitis. No time frame restrictions were placed for English language articles. Fifteen reports were found, describing 21 patients who developed parotitis after clozapine administration (Table 1). In most cases clozapine-induced parotitis developed shortly after initiation of the drug or as a result of increased doses of clozapine due to a new relapse. In some occasions ac- celerated titration was present. There were unilateral and bilateral cases, cases that were recurrent or occurred under one occasion. In most reports there was a relation between sialorrhea and clozapine-induced parotitis albeit a continuing debate exists in the literature over the exact cause-effect relation. In some cases co-occurring eosinophilia was present.

Whether sialorrhea generally precedes or follows clozapine-induced parotitis is still to be determined (24). After all, the main pathophysiological hypotheses trying to explain clozapine-induced parotitis are related to cell-mediated immune activation and inflammation. Hinze-Selch et al. (1996) proposed the immunologically mediated mechanism, suggesting that peripheral blood mononuclear cells sensitized to clozapine are associated with the development of sialadenitis, causing a swelling of the parotid glands (15). Vasile and Steingard (1995) hypothesized that the anticholinergic properties of clozapine may lead to thickening and stasis of saliva with precipitation of calcium salts leading to sialolithi-

Table 1. Case reports of suspected clozapine induced parotitis

\begin{tabular}{|c|c|c|c|c|c|}
\hline Reference & $\mathrm{N}$ patients & $\begin{array}{l}\text { CLZ dose } \\
\text { (mg/day) }\end{array}$ & $\begin{array}{l}\text { Modified } \\
\text { NPS score }\end{array}$ & $\mathrm{UL} / \mathrm{BL}$ & Hypersalivation \\
\hline Martin SD (1993) (11) & 1 & $400-600$ & 3 & $\mathrm{BL}$ & YES \\
\hline Robinson D et al. (1995) (12) & 2 & $300-600$ & 4 & $\mathrm{BL}$ & YES \\
\hline Vasile JS and Steingard S (1995) (13) & 4 & $25-150$ & $\mathrm{~N} / \mathrm{A}$ & $\mathrm{BL}$ & NO \\
\hline Davé M (1995) (14) & 2 & $600-675$ & 3 & UL & YES \\
\hline Hinze-Selch D et al. (1996) (15) & 1 & 200 & 6 & $\mathrm{BL}$ & YES \\
\hline Brodkin ES et al. (1996) (16) & 1 & 200 & 4 & $\mathrm{BL}$ & YES \\
\hline Patkar AA and Alexander RC (1996) (17) & 1 & 175 & 6 & $\mathrm{BL}$ & YES \\
\hline Southhall K and Fernando N (1999) (18) & 1 & 300 & 3 & UL & YES \\
\hline McKay D (2000) (19) & 1 & 150 & 6 & $\mathrm{BL}$ & YES \\
\hline Acosta-Armas AJ (2001) (20) & 2 & $275-900$ & $\mathrm{~N} / \mathrm{A}$ & $\mathrm{BL}$ & YES \\
\hline Immadisetty V and Agrawal P (2012) (21) & 1 & 300 & 7 & $\mathrm{BL}$ & YES \\
\hline Vohra A (2013) (22) & 1 & 175 & 9 & $\mathrm{UL}$ & NO \\
\hline Gouzien C et al. (2014) (23) & 1 & $350-500$ & 4 & $\mathrm{BL}$ & YES \\
\hline Saguem BN et al. (2015) (24) & 1 & 275 & 6 & $\mathrm{BL}$ & YES \\
\hline Jerónimo J et al. (2016) (25) & 1 & 400 & 5 & UL & YES \\
\hline Our case report & 1 & 200 & 6 & $\mathrm{BL}$ & YES \\
\hline
\end{tabular}

CLZ - Clozapine; NPS - Naranjo Probability Scale; UL - Unilateral; BL - Bilateral 
asis, consequent obstruction in the duct and finally, to the swelling of the salivary glands (13). In our case hypersalivation was present, although it was not declared as a problematic side effect by the patient. We suggested that both described pathophysiological mechanisms were involved in the development of the bilateral swelling of the parotid glands in our patient, so that biperiden was added to the treatment with a favorable outcome.

\section{CONCLUSION}

The swelling of the salivary glands is reported as a rare adverse effect of clozapine therapy and there could be various explanations for this: lack of awareness, as there are currently no treatment requirements for routine examinations of salivary glands in patients on clozapine treatment; low reporting of the condition as it is easy to miss or is more often observed in the fields of other medical specialties or low incidence of the event itself. However, further research will reveal more comprehensively the condition and its fundamental etiological mechanisms.

\section{REFERENCES}

1. Cheng F, Jones PB, Talbot PS. Antipsychotics. In: Anderson I, Hamish McAllister-Williams R, editors. Fundamentals of clinical psychopharmacology. 4th ed. Boca Raton, FL, USA: CRC Press; 2015. p. 47-76.

2. Leucht S, Corves C, Arbter D, Engel RR, Li C, Davis JM. Second-generation versus first-generation antipsychotic drugs for schizophrenia: a meta-analysis. Lancet. 2009; 373 (9657):31-41.

3. De Hert M, Detraux J, van Winkel R, Yu W, Correll CU. Metabolic and cardiovascular adverse effects associated with antipsychotic drugs. Nat Rev Endocrinol. 2011; 8(2):114-26. doi: 10.1038/ nrendo.2011.156.

4. Brooks KG, Thompson DF. A review and assessment of drug-induced parotitis. Ann Pharmacother. 2012; 46(12):1688-99. doi: 10.1345/aph.1R228.

5. Gershon A. Mumps. In: Fauci AS, Braunwald E, Kasper DL, et al., editors. Harrison's principles of internal medicine. $17^{\text {th }}$ ed. New York: McGrawHill; 2008. p. 1220-1.

6. De Fazio P, Gaetano R, Caroleo M, Cerminara G, Maida F, Bruno A, et al. Rare and very rare adverse effects of clozapine. Neuropsychiatr Dis Treat. 2015; 11:1995-2003. doi: 10.2147/NDT.S83989.
7. Arimone Y, Miremont-Salamé G, Haramburu F, Molimard M, Moore N, Fourrier-Réglat A, et al. Inter-expert agreement of seven criteria in causality assessment of adverse drug reactions. Br J Clin Pharmacol. 2007;64(4):482-8. doi: 10.1111/j.1365-2125.2007.02937.x.

8. The use of the WHO-UMC system for standardised case causality assessment. Accessed from: http://www.WHO-UMC.org

9. Naranjo CA, Busto U, Sellars EM, Sandor P, Ruiz I, Roberts EA, et al. A method for estimating the probability of adverse drug reactions. Clin Pharmacol Ther. 1981;30(2):239-45.

10. Naidu RP. Causality assessment: A brief insight into practices in pharmaceutical industry. Perspect Clin Res. 2013; 4(4):233-6. doi: 10.4103/2229-3485.120173.

11. Martin SD. Drug-induced parotid swelling. Br J Hosp Med. 1993; 50(7):426.

12. Robinson D, Fenn H, Yesavage J. Possible association of parotitis with clozapine. Am J Psychiatry. 1995;152(2):297-8. doi: 10.1176/ajp.152.2.297.

13. Vasile JS, Steingard S. Clozapine and the development of salivary gland swelling: a case study. J Clin Psychaitry 1995; 56(11):511-3.

14. Dave M. Iatrogenic salivary gland swelling. J Pharm Technol. 1995;11:18-20.

15. Hinze-Selch D, Becker EW, Stein G, Schreiber W, Pollmächer T. Clozapine-induced parotitis: an immunological cause? Am J Psychiatry. 1996;153(6):840.

16. Brodkin ES, Pelton GH, Price LH. Treatment of clozapine-induced parotid gland swelling. Am J Psychiatry. 1996;153(3):445.

17. Patkar AA, Alexander RC. Parotid gland swelling with clozapine. J Clin Psychiatry. 1996;57(10):488.

18. Southhall K, Fernando N. Report of a rare medical complication on clozapine. Aust NZ J Psychiat. 1999;33(1):122-3. doi: 10.1080/0004867900029.

19. McKay D. Perhaps not so rare? Aust NZ J Psychiat. 2000;34:340-1.

20. Acosta-Armas AJ. Two cases of parotid gland swelling in patients taking clozapine. Hosp Med. 2001;62(11):704-5.

21. Immadisetty $\mathrm{V}$, Agrawal P. A successful treatment strategy for clozapine-induced parotid swelling: a clinical case and systematic review. Ther Adv Psychopharmacol. 2012; 2(6):235-39. 
22. Vohra A. Clozapine- induced recurrent and transient parotid gland swelling. Afr J Psychiatry. 2013; 16(4):236-8.

23. Gouzien C, Valiamé A, Misdrahi, D. Clozapineinduced parotitis: a case study. L'encéphale. 2014; 40:81-5.

24. Saguem BN, Bouhlel S, Salem CB, Ben Hadj Ali B. Eosinophilia and parotitis occurring early in clozapine treatment. Int J Clin Pharm. 2015; 37:992-5.

25. Jerónimo J, Santos J, Bastos L. Uncommon effects of clozapine. Eur Psychiatry. 2016; 33:S614. 